\title{
Incidence, Survival, And Associated Factors Estimation In Osteosarcoma Patients With Lung Metastasis: A Single-Center Experience of 11 Years In Tianjin, China
}

Chao Zhang ( $\nabla$ drzhangchao@tmu.edu.cn )

Tianjin Medical University Cancer Institute and Hospital

Haixiao Wu

Tianjin Medical University Cancer Institute and Hospital

\section{Guijun Xu}

Tianjin Hospital

\section{Wenjuan Ma}

Tianjin Medical University Cancer Institute and Hospital

Lisha Qi

Tianjin Medical University Cancer Institute and Hospital

Zhijun Li

Tianjin Medical University Cancer Institute and Hospital

Jin Zhang

Tianjin Medical University Cancer Institute and Hospital

\section{Research Article}

Keywords: Osteosarcoma, Survival, Pulmonary metastasis

Posted Date: January 19th, 2022

DOI: https://doi.org/10.21203/rs.3.rs-1071152/v2

License: (9) (i) This work is licensed under a Creative Commons Attribution 4.0 International License. Read Full License 


\section{Abstract}

Background: Osteosarcoma is the most common primary malignant bone tumor. The current study was conducted to describe the general condition of patients with primary osteosarcoma in a single cancer center in Tianjin, China and to investigate the associated factors in osteosarcoma patients with lung metastasis.

Methods: From February 2009 to October 2020, patients from Tianjin Medical University Cancer Institute and Hospital, China were retrospectively analyzed. The Kaplan-Meier method was used to evaluate the overall survival of osteosarcoma patients. Prognostic factors of patients with osteosarcoma were identified by the Cox proportional hazard regression analysis. Risk factor of lung metastasis in osteosarcoma were investigated by the logistic regression model.

Results: A total of 203 patients were involved and 150 patients were successfully followed up for survival status. The 5 -year survival rate of osteo-sarcoma patients was $70.0 \%$. Surgery, bone and lung metastasis were the significant prognostic factors in multivariable Cox regression analysis. Twenty-one $(10.3 \%)$ patients showed lung metastasis at the diagnosis of osteosarcoma and $67(33 \%)$ lung metastases during the later course. T3 stage $(\mathrm{OR}=11.415,95 \% \mathrm{Cl} 1.362-95.677, \mathrm{P}=0.025)$ and synchronous bone metastasis ( $\mathrm{OR}=6.437,95 \% \mathrm{Cl} 1.69-24.51, \mathrm{P}=0.006)$ were risk factors of synchronous lung metastasis occurrence. Good necrosis $(\geq 90 \%, \mathrm{OR}=0.097,95 \% \mathrm{Cl} 0.028-0.332, \mathrm{P}=0.000)$ and elevated $\mathrm{Ki}-67(\geq 50 \%, \mathrm{OR}=4.529$, $95 \% \mathrm{Cl} 1.241-16.524, \mathrm{P}=0.022$ ) were proved to be significantly associated with metachronous lung metastasis occurrence.

Conclusion: The overall survival, prognostic factors and risk factors for lung metastasis in this single center provided insight about osteosarcoma management.

\section{Background}

Osteosarcoma is the most common primary malignant bone tumor in young adult, the prevalence was reported to be 8-11 per million people per year [1]. Since the comprehensive treatment strategy by chemotherapy and surgery, the 5-year overall survival rate has been significantly improved [2-3].

Distant metastasis, especially the lung metastasis, has been a serious issue in osteosarcoma management. Several studies have reported the negative effect of lung metastasis on survival in osteosarcoma [4-5]. The 5-year overall survival was just $20-30 \%$ in patients with lung metastasis [2]. A previous study, based on 1,408 patients with osteosarcoma in Surveillance, Epidemiology and End Results (SEER) database, reported a total of 238 patients (16.9\%) with lung metastases at diagnosis [6]. Similarly, the latest study showed that around $14 \%$ osteosarcoma patients were with lung metastasis at diagnosis and the indeterminate nodules in lung can turn into the metastatic disease at a median time of 5.3 months [7]. Lung metastasis has become the focus in osteosarcoma in recent years. 
Computerized tomography (CT) has been accepted to be the main strategy for the suspicious lung metastasis [7-8]. Due to the radiation exposure and mental burden, high frequency of lung CT is not considered in patients with low risk of lung metastasis. The differential diagnosis of benign and malignant in both the nodules $(<5 \mathrm{~mm})$ and indeterminate nodules has been treated as the challenging issue $[7,9-10]$. In the osteosarcoma patients with high risk of metastasis, PET-CT was recommended for its high sensitivity (90\%). Thus, risk evaluation on metastasis in osteosarcoma at diagnosis and during later course is important. The previous study reported that the large tumor size was associated with the higher odds of lung metastasis occurrence. Patients with tumor size larger than $371 \mathrm{~cm}^{3}$ showed a probability of $69 \%$ to suffer lung metastasis, compared with $34 \%$ in those with the smaller tumor size [11]. Axial location, tumor size $>10 \mathrm{~cm}$, higher $\mathrm{N}$ stage and bone metastasis presence were reported to be significant risk factors of lung metastasis in osteosarcoma [6]. These findings were valuable to identify the high-risk patients.

After widely literatures reviewing, most studies on osteosarcoma were performed based on Caucasian population. In China, with the development of Chinese Society of Clinical Oncology, the standardized treatment has been widely introduced and performed. As the first established department of bone and soft tissue sarcoma in China, we have the advantage to treat large population of osteosarcoma with the standardized chemotherapy and surgery by the same multidisciplinary team. Thus, we summarized our experience in the past ten years. Based on the single-center data, the survival and prognostic factors of patients with osteosarcoma were investigated. The incidences of both synchronous and metachronous lung metastasis were evaluated and the risk factors of lung metastasis were explored.

\section{Methods}

\section{Patient selection}

Based on medical records from February 2009 to October 2020, patients with historically diagnosed osteosarcoma were selected and followed by phone/clinic until December 2020. The inclusion criteria were listed as following: (a) historically diagnosed as primary osteosarcoma; (b) complete basic information; (c) clear evidence of lung metastasis. Patients were excluded if the survival status or lung metastasis was not available. Patients who cannot be followed were also excluded.

\section{Variables used in current study}

Variables were involved as following: age ( $\leq 18$ years, $19-40$ years, $\geq 41$ years), gender (male and female), tumor site (upper limb, lower limb, spine/pelvis), tumor grade (I-II, III-IV, or unknown), historical types (Group one including the conventional osteosarcoma, telangiectatic osteosarcoma, small cell osteosarcoma; Group two included low-grade central osteosarcoma, parosteal and periosteal osteosarcoma), surgery (no, salvage, amputation and unknown), necrosis (Huvos $\mathrm{I}-\mathrm{II}<90 \%$, Huvos IIIIV $\geq 90 \%$ ), alkaline phosphatase (ALP) level (normal, elevated in one time than the upper limitation, elevated more than two times), lactic dehydrogenase (LDH) level (normal and elevated), bone metastasis 
(no, synchronous, metachronous) and lung metastasis (no, synchronous, metachronous). Lung metastasis was diagnosed by lung CT according to the standard described by Tsoi KM [7].

\section{Statistics}

The survival time was described as mean \pm standard deviation. The categorical data were presented as the number and the percentage $(\mathrm{N}, \%)$. Pearson chi-square test was used to evaluate the difference between categorical variables. The main outcome was the overall survival (OS), which was defined as the time from the diagnosis of osteosarcoma to death by all causes. The patients with clear survival time were used to calculate the OS, 1-, 3-, and 5-year survival rates by the Kaplan-Meier method and the difference among variables were tested by the log-rank test. The prognostic factor associated with survival were investigated by the Cox proportional hazard regression analysis.

The risk factors of synchronous lung metastasis (SLM) were revealed by Logistic regression analysis. The patients with metachronous lung metastasis (MLM) were treated as patients without metastasis at diagnosis. Besides, the patients with metachronous bone metastasis (MBM) were treated as no bone metastasis at diagnosis. The factors at diagnosis of osteosarcoma were evaluated for prediction of lung metastasis. When exploring the risk factors of MLM, patients with SLM were excluded from the cohort.

Two-sided $P<0.05$ was considered as statistically significant. Variables with $P$-value $<0.05$ in the univariate regression analysis were further analyzed using a multivariate regression analysis. All statistical analyses were performed using SPSS 22.0 (IBM Corporation, NY, USA).

\section{Ethical statement}

This retrospective study was approved by the institutional research ethics committee of Tianjin Medical University Cancer Institute and Hospital (NO. bc2021011). All methods performed in the present study were in accordance with the ethical standards as laid down in the 1964 Declaration of Helsinki and its later amendments or comparable ethical standards. Informed consent was not required because no identifying details were in the current study.

\section{Results}

\section{General information}

A total of 237 patients were reviewed and patients were followed by phone/clinic. Follow-up time ranged from 2 to 144 months. Eventually, 203 patients were identified with the clear status of lung metastasis. The average age at diagnosis of osteosarcoma was 22.8 \pm 14.2 (5-77) years. The historical type one included 88 osteosarcoma NOS, 89 conventional osteosarcoma, 7 telangiectatic osteosarcoma, 3 small cell osteosarcoma; type two included 4 low-grade central osteosarcoma, 8 parosteal osteosarcoma and 4 periosteal osteosarcoma. Eighty-eight (43.3\%) patients were diagnosed with lung metastasis. Twenty-one pulmonary metastases $(10.3 \%$ ) were identified at the initial diagnosis of osteosarcoma while 67 patients 
(33\%) were found during the following treatment. The detail information about the distribution of osteosarcoma was summarized according to the status of lung metastasis in Table 1.

\section{Overall survival and prognostic factors}

The overall survival of all patients was $104.7 \pm 5.4$ [95\% Cl Confidence interval (Cl) $94.1-115.3]$ months. The $1-, 3-, 5$-year survival rate was $94.4 \%, 77.3 \%$ and $70 \%$, respectively. The survival of patients within different variables were shown in Table 2. For patients without lung metastasis, the average overall survival was $139.2 \pm 2.8(95 \% \mathrm{Cl} 133.7-144.6)$ months. The survival was worse in patients with lung metastasis: 33.3 $\pm 12.6(95 \% \mathrm{Cl}$ 8.6-57.9) months for SLM patients and 45.8 7.4 (95\% Cl 31.3-60.3) months MLM patients. The survival curve was shown in Figure 1A.

Univariable Cox regression identified the grade [III-IV, Hazard ratio $(\mathrm{HR})=8.235,95 \% \mathrm{Cl}$ 0.989-68.574, $P=0.051]$, N1 stage $(\mathrm{HR}=6.630,95 \% \mathrm{Cl} 1.962-22.401, P=0.002)$, MBM $(\mathrm{HR}=3.457,95 \% \mathrm{Cl} 1.756-6.805$, $P=0.000)$, SLM (HR=43.82, 95\% Cl 8.71-220.480, $P=0.000)$, MLM (HR=36.74, 95\% Cl 11.13-121.32, $P=0.000)$, and elevated ALP more than two times ( $\mathrm{HR}=2.453,95 \% \mathrm{Cl} 1.154-5.214, P=0.020)$ were the factors correlating with the worse survival. The salvage $(\mathrm{HR}=0.244,95 \% \mathrm{Cl} 0.081-0.728, P=0.011)$, amputation $(\mathrm{HR}=0.283,95 \% \mathrm{Cl} 0.092-0.870, P=0.028)$, and good tumor necrosis ( $\mathrm{HR}=0.085,95 \% \mathrm{Cl} 0.011$ $0.633, P=0.016)$ were the factors correlating with better survival. In multivariable Cox regression analysis, $\operatorname{SLM}(\mathrm{HR}=85.07,95 \% \mathrm{Cl}$ 8.71-220.480, $P=0.000)$, MLM (HR=73.18, 95\% Cl 12.42-431.24, $P=0.000)$ and salvage $(\mathrm{HR}=0.112,95 \% \mathrm{Cl} 0.026-0.478, P=0.003)$ were related with overall survival. More data about the Cox regression can be checked in supplementary Table 1.

\section{Lung metastasis and risk factors}

The median internal time from osteosarcoma diagnosis to lung metastasis in 63 MLM patients was 11 (2-99) months. The distribution of MLM was illustrated in Figure 1B. A total of 37 (58.7\%) MLM patients were found in the first year after diagnosis of osteosarcoma, 18 (28.6\%) patients in the second year, 8 $(12.7 \%)$ patients in the later time. Metastasectomy of the pulmonary lesion was performed in five patients. Chemotherapy was routinely scheduled.

The risk factors related with SLM in the univariate Logistic regression included T3 stage [Odds ratio $(\mathrm{OR})=9.429,95 \% \mathrm{Cl} 1.144-77.70, P=0.037]$ and synchronous bone metastasis (SBM) (OR=5.882, $95 \% \mathrm{Cl} 1.56-22.14, P=0.009)$. As to the patients with $\mathrm{MLM}$, histological Group two (OR=0.109, 95\% $\mathrm{Cl} 0.014-$ $0.85, P=0.035$ ), good necrosis ( $\geq 90 \%, \mathrm{OR}=0.113,95 \% \mathrm{Cl} 0.035-0.364, P=0.000)$, elevated $\mathrm{Ki}-67(\geq 50 \%$, $\mathrm{OR}=3.646,95 \% \mathrm{Cl} 1.169-11.373, P=0.026)$, elevated LDH (OR=2.171, 95\% Cl 1.125-4.190, $P=0.021)$ and elevated ALP more than two times $(\mathrm{OR}=2.241,95 \% \mathrm{Cl} 1.074-4.678, P=0.032)$ were associated with MLM occurrence. Details of the univariate Logistic regression were summarized in the supplementary Table 2. Multivariate Logistic regression confirmed that T3 stage ( $\mathrm{OR}=11.415,95 \% \mathrm{Cl} 1.362-95.677, P=0.025)$ and SBM (OR=6.437, $95 \% \mathrm{Cl} 1.69-24.51, P=0.006)$ were risk factors of SLM occurrence. Good necrosis ( $\geq 90 \%$, $\mathrm{OR}=0.097,95 \% \mathrm{Cl} 0.028-0.332, P=0.000)$ \elevated $\mathrm{Ki}-67(\geq 50 \%, \mathrm{OR}=4.529,95 \% \mathrm{Cl} 1.241-16.524, P=0.022)$, were proved to be significantly associated with MLM occurrence. 


\section{Discusion}

In the current study, we summarized our experience from 203 osteosarcoma patients. Based on the cohort, the 5-year survival rate was $70.0 \%$. Such long-term survival reached a promising level, which was better than that in our previous study based on SEER data from 2010 and 2016 [12].

Based on the univariate analysis, grade (III-IV), N1 stage, bone and lung metastasis, no surgery, tumor necrosis $<90 \%$ and elevated ALP more than two times were associated with worse survival. Surgery, bone and lung metastasis were proved to be the significant prognostic factors. Since 1970s, the introduction of chemotherapy significantly improved the survival of osteosarcoma patients. With the afterwards development of the innovated surgeries, the comprehensive treatment from multidisciplinary team was recommended [8]. In a recent meta-analysis, patients after limb-salvage surgery achieved better five-year survival rate than the patients after amputation with neoadjuvant chemotherapy [13]. Thus, the salvage surgery has become the first choice for eligible patients just did as the current study (salvage $52.2 \%$ vs. amputation 32\%). Chemotherapy and good tumor necrosis were another important issue in the treatment of osteosarcoma [14]. Chemotherapy response showed significant correlation with the long-term survival in osteosarcoma [15-16].

As previously reported $[5,17-18]$, the patients with lung metastasis showed poor survival. In the present study, the average overall survival of SLM patients, MLM patients and patients without lung metastasis were $33.3 \pm 12.6,45.8 \pm 7.4$ and $139.2 \pm 2.8$ months, respectively. The treatment of pulmonary metastatic lesions showed significant effect on the improved survival of osteosarcoma patients. The NCCN guidelines for bone cancer suggested surgery for the resectable lung metastasis [8]. Patients with less lesions, unilateral lung disease and patients after metastasectomy showed improved survival [19-20]. In our study, most patients with lung metastasis were offered chemotherapy instead of lung surgery. Gemcitabine, docetaxel and other new agents, including regorafenib [21] and apatinib [22], can be potential second-line choices. Low expectation of patient's family may be one of the reasons resulting in the limited performance of metastasectomy on lung metastatic lesions. With the accurate prediction of survival and benefit from metastasectomy on lung function improvement, the metastasectomy should be encouraged in the eligible patients.

Twenty-one (10.3\%) patients in the current study showed lung metastasis at the diagnosis of osteosarcoma, which was less than that previously reported [6, 23]. T3 stage and synchronous bone metastasis were risk factors for synchronous lung metastasis, accordance with the result from SEER [6]. During the median follow-up time of 49 months, 67 patients (33\%) were detected with lung metastasis. The average interval time from osteosarcoma to lung metastasis was $14.0 \pm 14.1$ months. Accordance with a previous study, most of lung metastasis happened in the first two or three years [24]. The proportion of patients with lung metastasis was $58.7 \%$ and $28.6 \%$ in the first and second year after osteosarcoma diagnosis, respectively. Thus, lung CT should be scheduled with high frequency in the first two years. In our current study, histological types in group one, bad necrosis rate, Ki- $67 \geq 50 \%$, elevated LDH and ALP were risk factors associated with higher odds of metachronous lung metastasis in the 
univariable analysis. Patients with the risk factors should be paid with more attention, especially the patients with bad necrosis response and $\mathrm{Ki}-67 \geq 50 \%$. A previous study found more lung metastases and bilateral lesions in patients after only surgery of primary tumor, compared with those after surgery plus chemotherapy [4]. Based on different risk of lung metastasis, lung CT plan can be more efficient.

Some limitations should be mentioned. Due to the long internal from osteosarcoma diagnosis, some patients were lost and cannot be reached. Limited size of the included patients and unknown information in some variables caused uncertainty in data statistics. The limitation of the retrospective study design also leads to weakness to draw confirming conclusions.

\section{Conclusions}

In summary, the osteosarcoma patients in our institute were effectively treated, with the 5-year overall survival of $70 \%$. The incidences of synchronous and metachronous lung metastasis were $10.3 \%$, and $33 \%$, respectively. The prognostic factors found in the current study can be significant on survival prediction. Risk factors of lung metastasis can be used to identify high-risk patients and guide individualized screening.

\section{List Of Abbreviations}

SEER: Surveillance, Epidemiology and End Results; CT: Computerized tomography; ALP: alkaline phosphatase; LDH: lactic dehydrogenase; OS: overall survival; SLM: synchronous lung metastasis; MLM: metachronous lung metastasis; MBM: metachronous bone metastasis; $\mathrm{Cl}$ : Confidence interval; HR: Hazard ratio; OR: Odds ratio; SBM: synchronous bone metastasis

\section{Declarations}

Acknowledgments: None

\section{Funding}

The present study was sponsored by Natural Science Foundation of China $(81801781,82011530050)$. All authors do not have any proprietary interests in the materials described in the article.

\section{Competing interests}

The authors declared no known competing financial interests or personal relationships in this study.

\section{Data availability}

The datasets used in the current study can be accessed from the corresponding author on reasonable request. 


\section{Code availability}

All statistical analyses in the present study were performed using SPSS 22.0 (IBM Corporation, NY, USA).

\section{Authors' contributions}

CZ, GJX and HXW collected, analyzed, and interpreted data; and drafted and wrote the manuscript. WJM, LSQ and ZJL supervised the collection and interpretation of radiological and histological information. CZ and $\mathrm{JZ}$ designed the research and supervised the data collection. All authors critically reviewed and revised the manuscript and approved the final manuscript.

\section{References}

1. Casali PG, Bielack S, Abecassis N, Aro HT, Bauer S, Biagini R, et al. Bone sarcomas: ESMO-PaedCanEURACAN Clinical Practice Guidelines for diagnosis, treatment and follow-up. ANN ONCOL. 2018;29(Suppl 4):v79-95. https://doi.org/ 10.1093/annonc/mdy310.

2. Ferrari S, Palmerini E. Adjuvant and neoadjuvant combination chemotherapy for osteogenic sarcoma. CURR OPIN ONCOL. 2007;19(4):341-6. https://doi.org/ 10.1097/CC0.0b013e328122d73f.

3. Goryń T, Pieńkowski A, Szostakowski B, Zdzienicki M, Ługowska I, Rutkowski P. Functional outcome of surgical treatment of adults with extremity osteosarcoma after megaprosthetic reconstructionsingle-center experience. J ORTHOP SURG RES. 2019;14(1):346. https://doi.org/ 10.1186/s13018019-1379-3.

4. Goorin AM, Shuster JJ, Baker A, Horowitz ME, Meyer WH, Link MP. Changing pattern of pulmonary metastases with adjuvant chemotherapy in patients with osteosarcoma: results from the multiinstitutional osteosarcoma study. J CLIN ONCOL. 1991;9(4):600-5. https://doi.org/ 10.1200/JC0.1991.9.4.600.

5. Ahmed G, Zamzam M, Kamel A, Ahmed S, Salama A, Zaki I, et al. Effect of timing of pulmonary metastasis occurrence on the outcome of metastasectomy in osteosarcoma patients. J PEDIATR SURG. 2019;54(4):775-9. https://doi.org/ 10.1016/j.jpedsurg.2018.06.019.

6. Zhang C, Guo X, Xu Y, Han X, Cai J, Wang X, et al. Lung metastases at the initial diagnosis of highgrade osteosarcoma: prevalence, risk factors and prognostic factors. A large population-based cohort study. SAO PAULO MED J. 2019;137(5):423-9. https://doi.org/ 10.1590/15163180.2018.0381120619.

7. Tsoi KM, Lowe M, Tsuda Y, Lex JR, Fujiwara T, Almeer G, et al. How Are Indeterminate Pulmonary Nodules at Diagnosis Associated with Survival in Patients with High-Grade Osteosarcoma? Clin Orthop Relat Res. 2021;479(2):298-308. https://doi.org/ 10.1097/CORR.0000000000001491.

8. Biermann JS, Chow W, Reed DR, Lucas D, Adkins DR, Agulnik M, et al. NCCN Guidelines Insights: Bone Cancer, Version 2.2017. J Natl Compr Canc Netw. 2017;15(2):155-67. https://doi.org/ 10.6004/jnccn.2017.0017. 
9. Kusma J, Young C, Yin H, Stanek JR, Yeager N, Aldrink JH. Pulmonary Nodule Size $<5 \mathrm{~mm}$ Still Warrants Investigation in Patients With Osteosarcoma and Ewing Sarcoma. J Pediatr Hematol Oncol. 2017;39(3):184-7. https://doi.org/ 10.1097/MPH.0000000000000753.

10. Liu F, Zhang Q, Zhou D, Dong J. Effectiveness of (18)F-FDG PET/CT in the diagnosis and staging of osteosarcoma: a meta-analysis of 26 studies. BMC CANCER. 2019;19(1):323. https://doi.org/ 10.1186/s12885-019-5488-5.

11. Munajat I, Zulmi W, Norazman MZ, Wan FW. Tumour volume and lung metastasis in patients with osteosarcoma. J Orthop Surg (Hong Kong). 2008;16(2):182-5. https://doi.org/ $10.1177 / 230949900801600211$.

12. Xu G, Wu H, Xu Y, Zhang Y, Lin F, Baklaushev VP, et al. Homogenous and Heterogenous Prognostic Factors for Patients with Bone Sarcoma. ORTHOP SURG. 2021;13(1):134-44. https://doi.org/ 10.1111/os.12851.

13. Papakonstantinou E, Stamatopoulos A, I AD, Kenanidis E, Potoupnis $M$, Haidich AB, et al. Limbsalvage surgery offers better five-year survival rate than amputation in patients with limb osteosarcoma treated with neoadjuvant chemotherapy. A systematic review and meta-analysis. $J$ BONE ONCOL. 2020;25:100319. https://doi.org/ 10.1016/j.jbo.2020.100319.

14. Kager L, Zoubek A, Pötschger U, Kastner U, Flege S, Kempf-Bielack B, et al. Primary metastatic osteosarcoma: presentation and outcome of patients treated on neoadjuvant Cooperative Osteosarcoma Study Group protocols. J CLIN ONCOL. 2003;21(10):2011-8. https://doi.org/ 10.1200/JC0.2003.08.132.

15. Lee I, Byun BH, Lim I, Kim BI, Choi CW, Koh JS, et al. Early response monitoring of neoadjuvant chemotherapy using [(18)F]FDG PET can predict the clinical outcome of extremity osteosarcoma. EJNMMI RES. 2020;10(1):1. https://doi.org/ 10.1186/s13550-019-0588-4.

16. Wu Y, Xu L, Yang P, Lin N, Huang X, Pan W, et al. Survival Prediction in High-grade Osteosarcoma Using Radiomics of Diagnostic Computed Tomography. EBIOMEDICINE. 2018;34:27-34. https://doi.org/ 10.1016/j.ebiom.2018.07.006.

17. Gok DA, Paksoy TF, Ardic YF, Tokluoglu S, Yazici OK, Demirci A, et al. Outcomes of Adolescent and Adult Patients with Lung Metastatic Osteosarcoma and Comparison of Synchronous and Metachronous Lung Metastatic Groups. PLOS ONE. 2016;11(5):e152621. https://doi.org/ 10.1371/journal.pone.0152621.

18. Li W, Zhang S. Survival of patients with primary osteosarcoma and lung metastases. J BUON. 2018;23(5):1500-4.

19. Gao E, Li Y, Zhao W, Zhao T, Guo X, He W, et al. Necessity of thoracotomy in pulmonary metastasis of osteosarcoma. J THORAC DIS. 2019;11(8):3578-83. https://doi.org/ 10.21037/jtd.2019.07.65.

20. Iwata S, Yonemoto T, lizasa T, Niibe Y, Kamoda H, Ishii T. Oligo-Recurrence of Osteosarcoma Patients: Treatment Strategies for Pulmonary Metastases. ANN SURG ONCOL. 2015;22 Suppl 3:1332-8. https://doi.org/ 10.1245/s10434-015-4682-1. 
21. Davis LE, Bolejack V, Ryan CW, Ganjoo KN, Loggers ET, Chawla S, et al. Randomized Double-Blind Phase II Study of Regorafenib in Patients With Metastatic Osteosarcoma. J CLIN ONCOL. 2019;37(16):1424-31. https://doi.org/ 10.1200/JC0.18.02374.

22. Zheng $\mathrm{K}$, Xu M, Wang L, Yu X. Efficacy and safety of apatinib in advance osteosarcoma with pulmonary metastases: A single-center observational study. Medicine. 2018;97(31):e11734. https://doi.org/ 10.1097/MD.0000000000011734.

23. Chou AJ, Geller DS, Gorlick R. Therapy for osteosarcoma: where do we go from here? Paediatr Drugs. 2008;10(5):315-27. https://doi.org/ 10.2165/00148581-200810050-00005.

24. Luetke A, Meyers PA, Lewis I, Juergens H. Osteosarcoma treatment - where do we stand? A state of the art review. CANCER TREAT REV. 2014;40(4):523-32. https://doi.org/ 10.1016/j.ctrv.2013.11.006.

\section{Tables}

Table 1 Demographic and clinical characteristics of the included patients 


\begin{tabular}{|c|c|c|c|c|c|}
\hline \multirow[t]{2}{*}{ Variables } & No & Synchronous & Metachronous & \multirow[t]{2}{*}{$x^{2}$} & \multirow[t]{2}{*}{$P$-value } \\
\hline & Lung Mets & Lung Mets & Lung Mets & & \\
\hline Age (year) & & & & 1.367 & 0.850 \\
\hline$\sim 18$ & $57(49.6 \%)$ & $11(52.4 \%)$ & 39 (58.2\%) & & \\
\hline $19-40$ & $43(37.4 \%)$ & $7(33.3 \%)$ & $21(31.3 \%)$ & & \\
\hline$\geq 41$ & $15(13.0 \%)$ & $3(14.3 \%)$ & $7(10.4 \%)$ & & \\
\hline Gender & & & & 1.817 & 0.403 \\
\hline Male & 64 (55.7\%) & 13 (61.9\%) & 44 (65.7\%) & & \\
\hline Female & $51(44.3 \%)$ & $8(38.1 \%)$ & $23(34.3 \%)$ & & \\
\hline Tumor site & & & & 4.218 & 0.377 \\
\hline Upper limb & $12(10.4 \%)$ & $4(19.0 \%)$ & $9(13.4 \%)$ & & \\
\hline Lower limb & $100(87.0 \%)$ & 15 (71.4\%) & $54(80.4 \%)$ & & \\
\hline Spine-pelvis & $3(2.6 \%)$ & $2(9.5 \%)$ & $4(6.0 \%)$ & & \\
\hline ICD-0-3 types & & & & 6.967 & 0.031 \\
\hline Group 1 & $101(87.8 \%)$ & $20(95.2 \%)$ & 66 (98.5\%) & & \\
\hline Group 2 & $14(12.2 \%)$ & $1(4.8 \%)$ & $1(1.5 \%)$ & & \\
\hline Grade & & & & 7.374 & 0.117 \\
\hline I+II & $23(20.0 \%)$ & $1(4.8 \%)$ & $5(7.5 \%)$ & & \\
\hline III+IV & $12(10.4 \%)$ & $2(9.5 \%)$ & $21(10.4 \%)$ & & \\
\hline Unknown & 80 (69.6\%) & $18(85.7 \%)$ & 55 (82.1\%) & & \\
\hline Stage $T$ & & & & 7.873 & 0.248 \\
\hline T1 & 43 (37.4\%) & 7 (33.3\%) & $23(36.0 \%)$ & & \\
\hline T2 & 68 (59.1\%) & 12 (57.1\%) & $42(60.1 \%)$ & & \\
\hline T3 & $1(0.9 \%)$ & $2(9.5 \%)$ & $1(2.0 \%)$ & & \\
\hline Unknown & $3(2.6 \%)$ & $0(0 \%)$ & $1(2.0 \%)$ & & \\
\hline Stage N & & & & 8.405 & 0.078 \\
\hline No & $81(70.4 \%)$ & $14(66.7 \%)$ & $44(65.7 \%)$ & & \\
\hline N1 & $0(0 \%)$ & $0(0 \%)$ & $4(6.0 \%)$ & & \\
\hline Unknown & $34(29.6 \%)$ & $7(33.3 \%)$ & 19 (28.4\%) & & \\
\hline
\end{tabular}


Bone Mets

$24.475 \quad 0.000$

\begin{tabular}{|c|c|c|c|c|c|}
\hline No & $100(87.0 \%)$ & 13 (61.9\%) & $46(68.7 \%)$ & & \\
\hline SBM & $6(5.2 \%)$ & $4(19.0 \%)$ & $1(1.5 \%)$ & & \\
\hline MBM & $9(7.8 \%)$ & $4(19.0 \%)$ & $20(29.9 \%)$ & & \\
\hline Surgery & & & & 47.557 & 0.000 \\
\hline No & $7(6.1 \%)$ & $10(47.6 \%)$ & $3(4.5 \%)$ & & \\
\hline Salvage & $64(55.7 \%)$ & $5(23.8 \%)$ & 31 (46.3\%) & & \\
\hline Amputation & $31(27.0 \%)$ & $4(19.0 \%)$ & $31(46.3 \%)$ & & \\
\hline Unknown & $13(11.3 \%)$ & $2(9.5 \%)$ & $2(3.0 \%)$ & & \\
\hline Chemotherapy & & & & 15.638 & 0.004 \\
\hline No & $5(4.3 \%)$ & $3(14.3 \%)$ & $0(0 \%)$ & & \\
\hline Yes & $93(80.9 \%)$ & $16(76.2 \%)$ & $65(97.0 \%)$ & & \\
\hline Unknown & $17(14.8 \%)$ & $2(9.5 \%)$ & $2(3.0 \%)$ & & \\
\hline Necrosis & & & & 26.393 & 0.000 \\
\hline$<90 \%$ & $26(22.6 \%)$ & $5(23.8 \%)$ & 34 (50.7\%) & & \\
\hline$\geq 90 \%$ & $27(23.5 \%)$ & $0(0 \%)$ & $4(6.0 \%)$ & & \\
\hline Unknown & $62(53.9 \%)$ & $16(76.2 \%)$ & $29(43.3 \%)$ & & \\
\hline Ki-67 & & & & 9.617 & 0.047 \\
\hline$<50 \%$ & $35(30.4 \%)$ & $3(14.3 \%)$ & $8(11.9 \%)$ & & \\
\hline$\geq 50 \%$ & $12(10.4 \%)$ & $2(9.5 \%)$ & $10(14.9 \%)$ & & \\
\hline Unknown & $68(59.1 \%)$ & $16(76.2 \%)$ & 49 (73.1\%) & & \\
\hline LDH & & & & 6.155 & 0.046 \\
\hline Normal & 89 (77.4\%) & $13(61.9 \%)$ & $41(61.2 \%)$ & & \\
\hline Elevated & $26(22.6 \%)$ & $8(38.1 \%)$ & $26(38.8 \%)$ & & \\
\hline ALP & & & & 6.172 & 0.187 \\
\hline Normal & $44(38.3 \%)$ & $8(38.1 \%)$ & 19 (28.4\%) & & \\
\hline Within one time & 40 (34.8\%) & $6(28.6 \%)$ & 18 (26.9\%) & & \\
\hline More than two times & $31(27.0 \%)$ & 7 (33.3\%) & $30(44.8 \%)$ & & \\
\hline
\end{tabular}


Abbreviations: Mets=Metastases; $\mathrm{SBM}=$ Synchronous bone metastasis; $\mathrm{MBM}=$ Metachronous bon metastasis; $\mathrm{ALP}=$ Alkaline phosphatase; $\mathrm{LDH}=$ Lactate dehydrogenase; NA=Not available.

Table 2 Overall survival of osteosarcoma patients in different variables.

Abbreviations: OSR=Overall survival rate; $A O S=$ Average overall survival; Mets=Metastases;

SBM/SLM=Synchronous bone/lung metastasis; MBM/MLM =Metachronous bone/lung metastasis; $A L P=$ Alkaline phosphatase; $L D H=$ Lactate dehydrogenase; $N A=$ Not available.

\section{Figures}
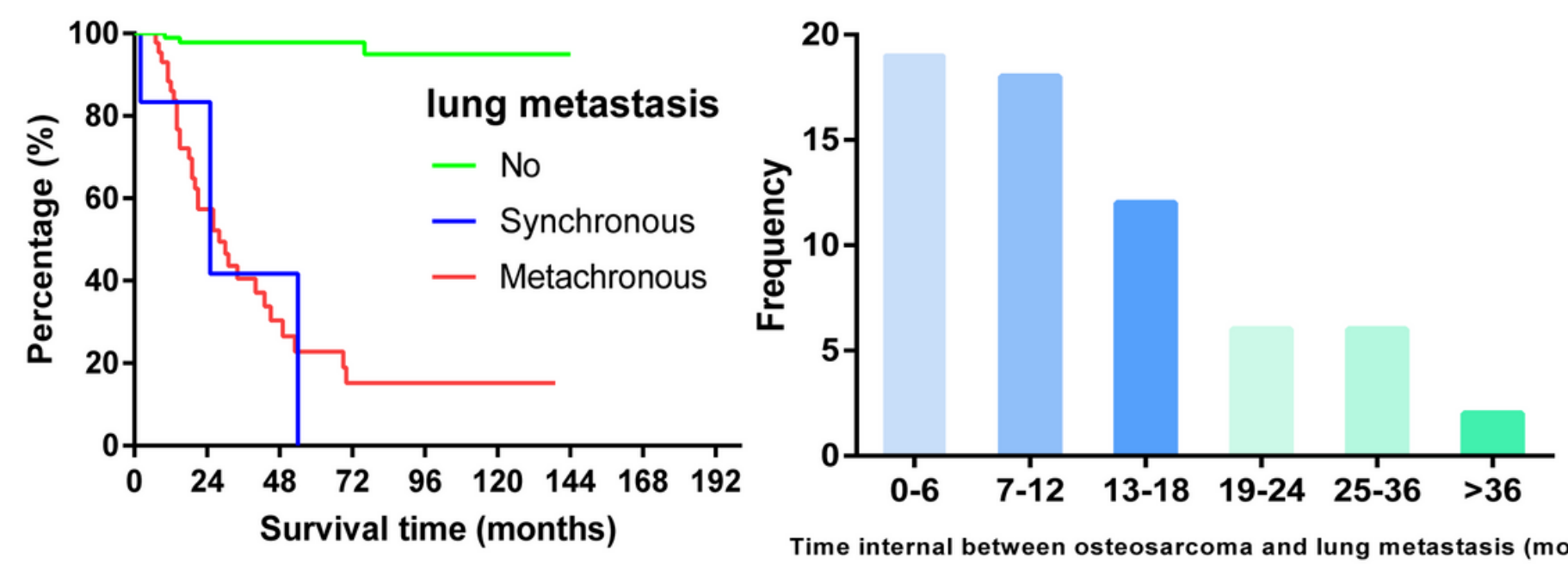

\section{Figure 1}

Survival and distribution of lung metastasis.

A. Survival for patients with or without lung metastasis. B. Time between osteosarcoma and lung metastasis

\section{Supplementary Files}

This is a list of supplementary files associated with this preprint. Click to download.

- supplementarytable1.docx

- supplementarytable2.docx 


\begin{tabular}{|c|c|c|c|c|c|}
\hline Variables & 3-year OSR & 5-year OSR & AOS $(95 \% \mathrm{Cl})$ months & $x^{2}$ & $P$-value \\
\hline Age (year) & & & & 1.989 & 0.370 \\
\hline$\sim 18$ & $72.9 \%$ & $59.6 \%$ & $91.9 \pm 7.6(77.0-106.8)$ & & \\
\hline $19-40$ & $83.3 \%$ & $80.6 \%$ & $113.1 \pm 7.7(98.0-128.1)$ & & \\
\hline$\geq 41$ & $73.6 \%$ & NA & $100.4 \pm 12.9(75.2-125.6)$ & & \\
\hline Gender & & & & 2.633 & 0.105 \\
\hline Male & $68.8 \%$ & $64.3 \%$ & $96.7 \pm 7.6(81.8-111.6)$ & & \\
\hline Female & $87.6 \%$ & $76.9 \%$ & $108.1 \pm 6.8(94.8-121.5)$ & & \\
\hline Tumor site & & & & 6.522 & 0.038 \\
\hline Upper limb & $66.7 \%$ & NA & $85.7 \pm 13.0(60.4-111.1)$ & & \\
\hline Lower limb & $80.0 \%$ & $71.8 \%$ & $106.9 \pm 5.7(95.7-118.1)$ & & \\
\hline Spine-pelvis & NA & NA & $26.4 \pm 5.5(15.7-37.2)$ & & \\
\hline ICD-0-3 types & & & & 2.921 & 0.087 \\
\hline Group 1 & $75.5 \%$ & $67.3 \%$ & $101.2 \pm 5.9(89.7-112.6)$ & & \\
\hline Group 2 & NA & NA & $124.6 \pm 8.1(108.7-140.5)$ & & \\
\hline Grade & & & & 5.037 & 0.081 \\
\hline $1+I I$ & NA & NA & $134.8 \pm 8.7(117.8-151.7)$ & & \\
\hline III+IV & $71.3 \%$ & $51.0 \%$ & $60.4 \pm 8.2(44.4-76.4)$ & & \\
\hline Unknown & $73.9 \%$ & $67.7 \%$ & $98.9 \pm 6.0(87.0-110.7)$ & & \\
\hline Stage $T$ & & & & 1.683 & 0.641 \\
\hline $\mathrm{T} 1$ & $84.0 \%$ & $69.4 \%$ & $98.2 \pm 8.3(82.0-114.5)$ & & \\
\hline $\mathrm{T} 2$ & $73.5 \%$ & NA & $98.3 \pm 6.4(85.8-110.9)$ & & \\
\hline T3 & NA & NA & $16.0 \pm 3.3(9.6-22.4)$ & & \\
\hline Unknown & NA & NA & $110.5 \pm 29.0(53.6-167.4)$ & & \\
\hline Stage N & & & & 12.595 & 0.002 \\
\hline No & $78.5 \%$ & $69.5 \%$ & $103.4 \pm 6.1(91.5-115.3)$ & & \\
\hline N1 & 0 & NA & $19.8 \pm 6.9(6.2-33.3)$ & & \\
\hline Unknown & $79.8 \%$ & $75.8 \%$ & $106.7 \pm 10.4(86.4-127.0)$ & & \\
\hline Bone Mets & & & & 14.620 & 0.001 \\
\hline
\end{tabular}




\begin{tabular}{|c|c|c|c|c|c|}
\hline No & $79.69 \%$ & $76.9 \%$ & $116.0 \pm 5.5(105.3-126.7)$ & & \\
\hline SBM & $83.3 \%$ & NA & $87.5 \pm 20.2(47.8-127.2)$ & & \\
\hline MBM & $64.7 \%$ & $43.1 \%$ & $64.6 \pm 10.9(43.12-86.0)$ & & \\
\hline Lung Mets & & & & 89.029 & 0.000 \\
\hline No & NA & NA & $139.2 \pm 2.8(133.7-144.6)$ & & \\
\hline SLM & $41.7 \%$ & 0 & $33.3 \pm 12.6(8.6-57.9)$ & & \\
\hline MLM & $40.5 \%$ & $22.8 \%$ & $45.8 \pm 7.4(31.3-60.3)$ & & \\
\hline Surgery & & & & 9.748 & 0.021 \\
\hline No & NA & NA & $57.4 \pm 16.6(24.9-89.9)$ & & \\
\hline Salvage & $75.6 \%$ & $69.6 \%$ & $101.6 \pm 6.7(88.4-114.7)$ & & \\
\hline Amputation & $80.7 \%$ & $70.2 \%$ & $101.2 \pm 9.1(83.5-119.0)$ & & \\
\hline Unknown & NA & NA & $78.3 \pm 5.5(67.6-89.0)$ & & \\
\hline Chemotherapy & & & & 1.692 & 0.429 \\
\hline No & NA & NA & NA & & \\
\hline Yes & $75.7 \%$ & $68.0 \%$ & NA & & \\
\hline Unknown & NA & NA & NA & & \\
\hline Necrosis & & & & 10.297 & 0.006 \\
\hline$<90 \%$ & $69.3 \%$ & $51.5 \%$ & $80.0 \pm 8.3(63.6-96.4)$ & & \\
\hline$\geq 90 \%$ & NA & NA & $130.0 \pm 4.9(120.5-139.6)$ & & \\
\hline Unknown & $76.2 \%$ & $72.6 \%$ & $108.7 \pm 7.6(93.8-123.7)$ & & \\
\hline Ki-67 & & & & 2.399 & 0.301 \\
\hline$<50 \%$ & $77.0 \%$ & NA & $92.5 \pm 9.7(73.5-111.5)$ & & \\
\hline$\geq 50 \%$ & NA & NA & $98.8 \pm 9.7(79.8-117.8)$ & & \\
\hline Unknown & $74.5 \%$ & NA & $99.9 \pm 6.4(87.3-112.6)$ & & \\
\hline LDH & & & & 0.554 & 0.456 \\
\hline Normal & $79.7 \%$ & $70.1 \%$ & $106.1 \pm 6.1(94.2-118.1)$ & & \\
\hline Elevated & $70.2 \%$ & NA & $97.8 \pm 10.9(76.5-119.1)$ & & \\
\hline ALP & & & & 8.150 & 0.017 \\
\hline Normal & $84.9 \%$ & $78.7 \%$ & $113.8 \pm 7.9(98.3-129.3)$ & & \\
\hline
\end{tabular}


Within one time

$80.9 \%$

More than two times
$64.0 \%$
NA

$51.8 \%$
$112.7 \pm 8.3(96.5-129.0)$

$75.0 \pm 9.1(57.1-92.8)$ 